\title{
Contribuições da literatura brasileira contemporânea ao "livro de registro da cidade"
}

Vera Lúcia Cardoso Medeiros ${ }^{1}$

Obra da mão humana, no que se contrapõe à natureza, a cidade firmou-se, ao longo da história, como modo de vida dotado de características bastante específicas, em geral associadas à ideia de modernidade, tornando seu habitante paradigma do sujeito moderno, condição que se mantém neste século XXI. Campo riquíssimo de estudos para as ciências humanas, uma vez que "é objeto de múltiplos discursos e olhares, que não se hierarquizam, mas que se justapõem, compõem ou se contradizem, sem, por isso, serem uns mais verdadeiros ou importantes que os outros" (Pesavento, 1999 , p. 10), a cidade tem sido examinada como texto, "livro de registro" no qual está fixado tudo o que ela produz e contém - "documentos, ordens, inventários, mapas, diagramas, plantas baixas, fotos, caricaturas, crônicas, literatura... que fixam sua memória." (Gomes, 1994, p. 23) - e que sintetiza os muitos modos de vê-la e representá-la. Mais do que resultado do trabalho humano, a cidade assume a condição de "lugar e metáfora, produzindo uma cartografia dinâmica, tensão entre racionalidade geométrica e emaranhado de existências humanas" (Gomes, 1994, p. 24).

A leitura do complexo texto da cidade, suas ruas, cruzamentos e labirintos, seus sujeitos e as relações aí estabelecidas, desde há muito se detém sobre a obra literária como fonte privilegiada de representação e registro da vida urbana e suas implicações na constituição de sujeitos e sociedades, o que se justifica, de acordo com a historiadora Sandra Pesavento, pela capacidade que tem o olhar literário para reconstruir a cidade de pedra:

Há, pois, uma realidade material - da cidade construída pelos homens, que traz as marcas da ação social. É o que chamamos cidade de pedra, erguida e recriada através dos tempos, derrubada e transformada em sua forma e traçado.

Sobre tal cidade, ou em tal cidade, se exercita o olhar literário, que sonha e reconstrói a materialidade da pedra sob a forma de um texto. O escritor, como espectador privilegiado do social, exerce a sua sensibilidade para criar uma cidade do pensamento, traduzida em palavras e figurações mentais imagéticas do espaço urbano e de seus atores (Pesavento, 1999, p. 10).

\footnotetext{
${ }^{1}$ Doutora em letras - literatura brasileira e professora adjunta da Universidade Federal do Pampa (Unipampa), Bagé, RS, Brasil. E-mail: veramedeiros@unipampa.edu.br
} 
No caso específico da literatura brasileira, tanto as formas líricas quanto as narrativas forneceram várias páginas ao "livro de registro" da cidade, já que fixaram e problematizaram desde os momentos iniciais de formação da vida urbana, passando pelas diferentes etapas da consolidação desse modelo, até a constituição de grandes metrópoles, índices da modernização nacional, a ponto de ser possível escrever a história da literatura brasileira por meio da representação do fenômeno urbano e suas implicações. Entre os vários escritores brasileiros que se dedicaram a ler a cidade, está Clarice Lispector, autora de obras de ficção cujos enredos desenrolam-se prioritariamente em espaços urbanos que não se limitam à função de cenário, mas assumem função importante na construção das personagens e de suas relações.

A literatura de Lispector, produzida entre as décadas de 1940 e 1970, é eminentemente urbana, e, na grande maioria dos casos, é aí que se desenrola toda a trama. São cidades inventadas ou existentes, com notável predomínio de referências explícitas à cidade do Rio de Janeiro. Nos anos 40 do século passado, quando surgem Perto do coração selvagem (1943), O lustre (1946) e A cidade sitiada (1949), período que se segue à implantação do Estado Novo (1937), há no país um esforço em prol da modernização, a que estão indissoluvelmente associadas urbanização e industrialização. Portanto, os primeiros romances de Clarice já são produzidos e publicados em momento em que a histórica primazia do campo sobre a cidade está se alterando. Nos anos 1950, a escritora publica apenas um pequeno volume de contos, mas, a partir dos anos 1960, sua produção torna-se frequente e diversificada: são contos, romances, crônicas e outros escritos. Nesse período, o Brasil que importa é eminentemente urbano.

Com base, então, no cotejo das datas de publicação dos títulos de Clarice Lispector e das etapas do processo de urbanização do país, chega-se a algumas constatações. Escrita no período em que o espaço urbano começa a conquistar primazia em relação ao rural, sua ficção não flagra a euforia diante da cidade, suas máquinas, ruídos e vapores, ao contrário do que é observado em obras lançadas nas primeiras décadas do século XX. É de modo gradual que as personagens de Lispector tornam-se parte da cena urbana, como se o conjunto dessa obra permitisse acompanhar o percurso de adaptação da sociedade brasileira ao estilo urbano de vida, marcado por valores e comportamentos bastante distintos daqueles predominantes no ambiente não urbano. Se as protagonistas dos romances O lustre, de 1946, e A cidade sitiada, de 1949, deixam seus lugares de origem - uma vila e um subúrbio, respectivamente - e não se adaptam às grandes cidades, o que se torna decisivo para o desfecho das obras, os contos e romances 
posteriores flagram situações em que não há possibilidade de retorno, e sujeito e cidade estão imbricados.

O aspecto da vida urbana mais enfatizado na representação na ficção de Lispector é a rua, a qual oferece ao sujeito encontros impossíveis de ocorrerem em outros ambientes por ser nela que convivem as cidades dentro da cidade. ${ }^{2}$ É quando saem à rua que as personagens passam por processo de desestabilização de certezas e sentidos, em especial do olhar. É ainda nesse espaço que sujeitos recuperam suas identidades, principalmente as mulheres, habitualmente confinadas ao ambiente doméstico, reclusas e protegidas pelo lar.

"Amor", "A bela e a fera ou a ferida grande demais", "Ele me bebeu", "A mensagem" são alguns dos muitos contos em que a rua é espaço crucial da ação e revelam o quanto Clarice Lispector soube ler a sociedade brasileira a partir desse lugar. Somente aí seria possível encontrar e interagir com a alteridade, perceber-se pelo confronto com o diferente e desconhecido e viver momentos - ainda que transitórios - de autoconhecimento.

É interessante ressaltar que a cartografia da cidade desenhada por Clarice Lispector não tem muitos registros da multidão, ao contrário do que se observa em outros leitores/escritores da cidade. Em geral, o que atrai o olhar é um ser ou objeto localizado a certa distância dos passantes, ficando o observador à parte dos demais transeuntes, não sendo possível ver nele a figura do caminhante que circula com naturalidade entre a multidão e sintetizado na imagem do flâneur. Esse modo distraído e sem rumo de estar à rua é mais frequente nas obras iniciais da escritora, ao contrário do observado em escritos posteriores, quando as personagens ocupam o espaço da rua por algum motivo definido, mesmo que seja uma espera. Essa pequena alteração no modo de estar à rua pode ser explicada porque entre os anos de 1940 e 1970, quando Lispector escreve seus textos, a rua deixa de ser espaço estranho, a novidade que atrai as personagens que chegam ao grande centro urbano, e vai tornando-se local de trânsito obrigatório, plenamente incorporado à rotina dos habitantes das metrópoles.

As crônicas escritas para o Jornal do Brasil e publicadas em A descoberta do mundo testemunham a vida que pulsa por ruas, bairros e cantos das várias cidades em que Clarice Lispector viveu, especialmente do Rio de Janeiro, por onde perambula entre a Zona Norte e a Sul, por São Cristóvão, Olaria, Grajaú, Bonsucesso, Floresta da Tijuca, Leblon, Jardim Botânico, Praça Mauá, Cemitério São João Batista, Botafogo, Urca, Corcovado, Central do Brasil, ponte Rio-Niterói, Posto 6, Copacabana. Enfim, a escritora

\footnotetext{
${ }^{2}$ Marques Rebelo, em entrevista a Clarice Lispector, assim refere-se à cidade do Rio de Janeiro: "O Rio é uma cidade com muitas cidades dentro" (Lispector, 1992, p. 39).
} 
circula por toda a metrópole, recolhendo sua alma, nem sempre encantadora, por meio de perfis, tipos, corpos, palavras, imagens e cenas que alimentam essa ficção. Esse modo de andar transforma a cidade em lugar e metáfora, ideia que Renato Cordeiro Gomes desenvolve no ensaio Todas as cidades, a cidade, estudo da metrópole moderna, notadamente do Rio de Janeiro e de alguns de seus leitores, como João do Rio e Marques Rebelo. No fragmento transcrito a seguir, o autor comenta a modernização carioca imposta pelo poder público.

Impunha-se a demolição da cidade velha para construir o cenário moderno. A literatura que representa este processo é filha da cidade, que experimenta novos ritmos e ganha reputação de centro de mudanças intelectuais e culturais. Escrever/ler o Rio de Janeiro era, desta forma, conjugar experiência urbana e modernidade. Mais que lugar de encontros acidentais, espaços do efêmero, ou pontos de cruzamento, a cidade é ambiente de mudanças, de rupturas, pontos focais da comunidade intelectual. E, ainda mais, de conflitos e tensões de vários matizes. É tanto metáfora como lugar (Gomes, 1994, p. 105).

Essa dupla função da cidade pode ser observada em "A procura de uma dignidade", conto publicado em Onde estivestes de noite, curioso livro publicado em 1974. Nele a personagem principal, mulher de quase setenta anos, entra, sem saber como, no Maracanã, indo parar nos subterrâneos do estádio vazio como se estivesse em um labirinto:

Então a senhora seguiu por um corredor sombrio. Este a levou igualmente a outro mais sombrio. Pareceu-lhe que o teto dos subterrâneos eram baixos.

E aí este corredor a levou a outro que a levou por sua vez a outro.

Dobrou o corredor deserto. E aí caiu em outra esquina. Que a levou a outro corredor que desembocou em outra esquina (Lispector, 1980, p. 7-8).

Ao percorrer os corredores, a mulher depara-se com repentinas aparições que contribuem para a atmosfera insólita que cerca o conto, intensificada pela visão do "estádio nu desventrado, sem bola nem futebol. Sobretudo sem multidão. Havia uma multidão que existia pelo vazio de sua ausência absoluta" (Lispector, 1980, p. 9).

A imagem do Maracanã vazio em uma quente tarde de inverno condensa sequência de situações estranhas e absurdas, todas envolvendo a cidade e sua geografia e entrelaçando-se, ao final, à personagem. Trata-se, portanto, da representação da cidade e seu monumento como lugar e metáfora. O estádio - símbolo da pujança nacional, índice do sucesso do país, construído para abrigar multidões e ser o maior do mundo -, 
quando vazio, perde sua função original de espaço de lazer da multidão na metrópole. Associado à figura do labirinto, surge como lugar de dispersão e angústia, servindo de exemplo a comentário de Renato Cordeiro Gomes: "Invertendo-se uma das interpretações do mito, o labirinto aqui não é trilha para chegar-se ao centro; é, antes, marca da dispersão. Indica a vitória do material sobre o espiritual, do perecível sobre o eterno. $\mathrm{Ou}$ mais, o lugar do descartável e do novo sempre igual" (Gomes, 1994, p. 64).

O célebre romance A paixão segundo G.H. (1964) também se refere ao tema da cidade e explicita a necessidade de cartografá-la, conforme demonstra trecho abaixo:

Pois eu estava procurando o tesouro de minha cidade.

Uma cidade de ouro e pedra, o Rio de Janeiro, cujos habitantes ao sol eram seiscentos mil mendigos. $O$ tesouro da cidade poderia estar numa das brechas do cascalho. Mas qual delas? Aquela cidade estava precisando de um trabalho de cartografia.

Subindo com o olhar para cada vez mais longe, por elevações sempre mais escarpadas, diante de mim jaziam gigantescos blocos de edifícios que formavam um desenho pesado, ainda não indicado num mapa (Lispector, 1986, p. 101).

O processo de conhecimento e revelação de verdades vivido por G.H. dá-se em paralelo ao trabalho de descoberta de sua cidade, dotada de nome e paisagem, morros, sol, edifícios, guindastes, construções, a massa que vai e vem; seus contornos sociais transparecem sob a forma de favelas e mendigos, embora o termo se aplique a todos os habitantes da cidade, indicando que não se mendiga apenas dinheiro.

Diante da imagem da sua cidade, o Rio de Janeiro, a mulher percebe que seus tesouros - os da cidade, os dela - podem estar em brechas do cascalho, assim como sua verdade está sob um armário velho e empoeirado. O trabalho de cartografia, o novo mapa da cidade, deve mostrar aquilo que só é localizado quando se olha bem pra baixo ou bem pra cima, deslocando o olhar das imagens habituais. Ora, a nova imagem da cidade constrói-se junto com o nascimento da nova G.H. A mulher e a cidade desenham-se paralelamente, e aí está novamente a articulação entre sujeito e cidade.

Em síntese, na obra de Clarice Lispector a cidade é lida como espaço de contradições e ambiguidades, em cujas ruas e avenidas os sujeitos têm a oportunidade de viverem encontros impensáveis nos demais espaços em que circulam, e daí resultam choques, descobertas, transformações. A cidade é labirinto, emaranhado de ruas que dispersam o sujeito em vez de conduzi-lo a algum lugar, mas também pode ser ponto de apoio para sua construção. Em todo caso, sujeito e cidade estão profundamente im- 
bricados, e a cidade é resultado do trabalho humano tanto quanto o sujeito é produto das cidades em que viveu.

Ao ler "o livro de registro da cidade", a escritora Clarice Lispector procurou focalizar as várias cidades que compõem uma mesma cidade, encarando-a sem euforia, mas também valorizando-a como espaço para encontros e cruzamentos entre os indivíduos. Suas rotas de leitura da cidade certamente serviram a muitos que se dedicaram à compreensão do fenômeno urbano no Brasil no período entre 1940 e 1970, contudo, será que a cidade, no início do século XXI, ainda pode ser retratada através dos mesmos caminhos percorridos pela escritora? As metáforas que, na ficção de Lispector, traduziram a vida urbana, são ainda significativas para conceituar a cidade e suas articulações?

Fomos buscar possíveis respostas a essas indagações em Prosas cariocas: uma nova cartografia do Rio de Janeiro, coletânea de contos publicada em 2004 que pretende "utilizar a literatura para descortinar diferentes bairros da cidade, palcos por onde os cariocas transitam e trafegam, de casa para o trabalho ou para o lazer" (Moutinho e Izhaki, 2004, p. 11). Para tanto, dezessete jovens autores foram selecionados pelos organizadores da obra para escrever sobre um bairro da do Rio de Janeiro, proporcionando uma leitura bastante contemporânea da cidade e suas repercussões - ou não sobre os sujeitos.

O livro fixa algumas das formas de perceber a cidade contemporânea, as relações entre esta e seus habitantes e os elementos que atraem o olhar do observador em narrativas que propõem leitura bastante ampla do cenário urbano e mostram que a cidade continua sendo elemento determinante na vida dos que nela habitam, assim como as ruas seguem sendo espaços que proporcionam encontros inusitados, o que não impede, porém, o surgimento de novos elementos na composição do "livro de registro da cidade". Em comparação com o corpus antes analisado, a obra de Clarice Lispector, verifica-se que o cenário urbano brasileiro do século XXI é composto por grandes condomínios e vidas compartilhadas compulsoriamente com uma vizinhança numerosa e anônima; pela violência; pelo aprofundamento das diferenças entre zonas e bairros, criando muitas e diversas cidades; e ainda pela importância que se atribui ao deslocamento entre bairros e zonas da cidade e principalmente aos meios de transporte, residindo aí um dos aspectos mais recorrentes na representação da cena urbana brasileira.

Do conjunto dos contos de Prosas cariocas depreende-se que, na contemporaneidade, mover-se por transporte coletivo, táxi ou veículo particular passou a definir o tipo de experiência do sujeito na cidade e 
tornou-se um dos motivos recorrentes na representação literária, ainda que sua importância na trama ou na constituição dos personagens seja bastante variável.

"Quando se muda", conto de Bianca Ramoneda, traça um paralelo entre a trajetória da narradora e os diferentes veículos adquiridos, como se cada novo modelo - moto, fusca, parati 92 - correspondesse a uma etapa de sua vida. $\mathrm{O}$ anseio por liberdade está expresso na imagem da moto usada comprada no morro do Formiga, que lhe permite ultrapassar os limites de seu bairro, ainda com ares de cidade do interior, como ilustra o próximo fragmento: "Lindo bairro para morar, se a sua ideia for passar os dias e, principalmente, as noites dentro de casa. Como uma legítima cidade do interior, na Muda o transporte acaba antes da 22 horas e é impossível comer um salgadinho onde quer que seja, pois não há nada aberto" (Ramoneda, 2004, p. 51).

De sua moto, a narradora pode chegar à universidade e ter uma visão diferenciada da cidade:

Sobre essas duas rodas, eu, como uma versão feminina de um Vital do subúrbio carioca, ia pela Radial Oeste comendo poeira para entrar naquele bloco de concreto quente chamado Universidade do Estado do Rio de Janeiro. Lá de cima, uma outra visão da cidade, lindos tons de céu, o movimento de quem vai e volta do trabalho socado no trânsito (Ramoneda, 2004, p. 52).

O desenho da cidade ressalta os tons do céu, característica em geral atribuída à descrição do espaço, e o trânsito movimentado e pouco confortável na volta do trabalho, construindo uma imagem contrastante de beleza e opressão.

Contrastantes são ainda as experiências adquiridas nas andanças pela cidade, que tem a moto por testemunha, em lugar de amigos ou namorados: "Sobre essa moto vivi algumas das minhas maiores alegrias e também horrores. Com ela desbravei a zona sul” (Ramoneda, 2004, p. 52). O próximo veículo, um fusca considerado cult pelas amigas da Zona Sul, foi igualmente parceiro - "Foram raros os barros da cidade onde não estacionei meu fusca caramelo" (Ramoneda, 2004, p. 53) - até ser abandonado junto com o namoro iniciado ao comprar o carro.

Nova etapa da vida, outro veículo, agora a Parati 92, cujo enorme porta-malas comportava livros, fantasias, projetos presentes e futuros: “Todos os meus sonhos cabiam ali, e ela me levava para os que não cabiam" (Ramoneda, 2004, p. 54). Esse veículo prestou-se a passeios noturnos pela cidade, e seus vidros serviam de enquadramento para pensamentos e cenário:

Às vezes saía pela noite adentro sem rumo, sozinha, pra pôr as ideias em ordem com a paisagem em movimento. É melhor do que 
pensar parada. À noite, pensamentos e bairros emoldurados pelo vidro, cenas entrecortadas, os sinais que não devem ser respeitados. A cidade é outra durante a madrugada, os rostos miseráveis saem das entranhas de concreto e se misturam ao cinza (Ramoneda, 2004, p. 55).

No excerto acima, percebe-se a importância do movimento como forma de organização mental e de percepção do que está à volta, embora o resultado da percepção em movimento sejam "cenas entrecortadas", através das quais não se consegue a visão do todo. Mais do que importante, o movimento é uma certeza em qualquer zona da cidade, sugere o próximo trecho: "Morando no Leblon descobri que o sofrimento é móvel e está em toda parte. Que não se está protegido dele em lugar nenhum" (Ramoneda, 2004, p. 57).

"A varredura" é o título do conto que Juva Batella escreve sobre o bairro do Leblon, composição interessante por mostrar a rua e a cidade pela ótica dos varredores, os quais encontram nos carros uma ameaça constante a ponto de interferir em suas tarefas: "A melhor varredura é a que se faz no sentido contrário aos dos carros, que desse modo podem ser vistos e evitados, principalmente quando chove e faz poças dos lados" (Batella, 2004, p.78).

Dentre os veículos que parecem definir um modo de ser, ver e ser visto, o ônibus tem evidente destaque, concentrando muitos aspectos do fenômeno urbano neste século e ocupando talvez a função que a rua assumiu desde o final do século XIX enquanto espaço eminentemente urbano de testemunha e motivação de importantes transformações individuais ou coletivas. Em vários contos de Prosas cariocas, o mundo e o outro são percebidos através das janelas do coletivo e as emoções do sujeito são traduzidas por meio de vocabulário oriundo a seu universo. Esse é o caso de "Translúcida", de Henrique Rodrigues, em que o narrador contempla a cidade através das vidraças de um ônibus em movimento, ao final de sua jornada de trabalho. Em pé, ele observa a cidade ao mesmo tempo que acompanha, pelos reflexos do vidro, Aurora, sua companheira cotidiana no coletivo, por quem nutre silenciosa admiração. Dessa posição o narrador tem uma visão invertida de si e da cidade, "espécie de cinema ao avesso": "O que há lá fora, pelo menos o que consigo vislumbrar todos os dias, é uma espécie de cinema ao avesso: imagens em movimento que, ao passar rapidamente, dão a impressão de que tudo é estático" (Rodrigues, 2004, p. 59). Quem olha através da janela do ônibus - “a janela é um painel imagético de situações fragmentadas" (Rodrigues, 2004, p. 60) - não consegue apreender o todo, seja ele uma rua, um bairro ou a cidade, e desse 
"caixote de anônimos" - o ônibus - são vistas partes de um todo bastante volátil, a cidade contemporânea.

"Para ver as meninas" é a narrativa dedicada ao bairro da Urca, de Marcelo Moutinho, em que proliferam imagens que condensam as imbricações entre o sujeito e o coletivo em que ele se movimenta. Nas linhas iniciais, o narrador afirma detestar chavões, entre os quais está um que define "o flanar como paradoxal caminho para descobertas interiores" (Moutinho, 2004, p. 97). Apesar da opinião manifestada de forma clara, o próprio narrador sabe que entrará em contradição, uma vez que toma um ônibus para "gastar as horas pela cidade", após ser demitido do emprego. Tanto o ponto em que tomará o coletivo quanto o próprio veículo desencadeiam várias perguntas:

Chegando ao ponto, olhei para a avenida apinhada de gente, mais partidas do que chegadas. Para onde vão todas aquelas pessoas? O que querem? Amor, grana, putaria, casamento, veleidades, carros novos? Quando subi no ônibus, o primeiro que passou, pensei rapidamente que seria bom não ter trabalhos pendentes, apenas uma nova e inútil paisagem. Pensei, enfim. E era só o que faria a partir dali: pensar, pensar, pensar, pensar, pensar, pensar, pensar, pensar, pensar, pensar,pensar, pensar, pensar, pensar, pensar, pensar, pensar, pensar, pensar, pensar, pensar, pensar, pensar,pensar,pensar, pensar,pensar por linhas e linhas, por horas e horas, cutucando os neurônios até enfim encontrar aquilo que se perdeu (Moutinho, 2004, p. 98).

Na ficção de Clarice Lispector, examinada anteriormente como importante elemento na constituição do "livro de registro" da cidade brasileira, era quando saíam às ruas que os personagens, em sua grande maioria mulheres, tinham a oportunidade de encontrar o outro e de refletir sobre sua condição, ao passo que, na leitura contemporânea de Moutinho, entre tantos outros autores de Prosas cariocas, o transporte coletivo torna-se espaço para encontros e confrontos. Constata-se que a presença desse elemento intrínseco à vida nas grandes cidades, o ônibus, gera novas comparações e metáforas capazes de traduzir as relações entre os sujeitos e o espaço urbano, como as enumeradas a seguir: "Eu detesto trabalhar assim, puto da vida, cheio de engarrafamento" (Moutinho, 2004, p. 99); "O que acontecia lá fora repercutiu dentro do meu ônibus" (Moutinho, 2004, p. 104). O comentário do narrador sobre o futuro da criança sentada a seu lado é outro exemplo de construção em que a trajetória do veículo expressa o movimento da vida: "se um dia também entraria num ônibus e no trânsito engarrafado ficaria se cutucando atrás de razões maiores para levar adiante" (Moutinho, 2004, p. 105). 
Em A modernidade líquida, Zygmunt Bauman caracteriza os fluidos como aquelas substâncias que não fixam espaço nem tempo, estão sempre prontas para mudanças, e ocupam o espaço por momentos: "os fluidos se movem facilmente". Tais qualidades "são razões para considerar 'fluidez' ou 'liquidez' como metáforas adequadas quando queremos captar a natureza da presente fase, nova de muitas maneiras, na história da modernidade" (Bauman, 2001, p. 9). Bauman ressalta que, embora a associação entre movimento e modernidade não seja nova, na contemporaneidade - vale registrar que seu estudo teve a primeira publicação no ano 2000 -, as ideias de liquidez e fluidez sobrepõem-se a qualquer tentativa de "substituir o conjunto herdado de sólidos deficientes e defeituosos por outro conjunto, aperfeiçoado e preferivelmente perfeito, e por isso não mais alterável" (Bauman, 2001 , p. 9). Isto explicaria a forma de percepção e ação dos protagonistas de contos como "Quando se muda" e "Translúcida", que não aspiram a posições fixas. No conto de Bianca Ramoneda, a narradora, depois de já ter morado em diversos bairros da cidade, conclui: "Circulo achando graça dos códigos e me adapto momentaneamente a qualquer um deles, para facilitar" (Ramoneda, 2004, p. 58). Em "Translúcidas", o narrador reconhece que é "o verdadeiro elemento transitório" (Rodrigues, 2004, p. 60). Portanto, o anseio por mobilidade e movimento e a recusa por posições fixas, identificados nesses contos, mergulha seus personagens no contexto da modernidade líquida a que o sociólogo polonês dedicou vários estudos.

Ainda em relação às posições cambiantes que podem ser ocupadas pelos sujeitos em deslocamento, vemos que, nas narrativas de Prosas cariocas, estar dentro do ônibus altera a condição do sujeito - dentro, é passageiro; fora, é o passante. Cada posição assegura um ponto de observação e leitura do contexto, e a articulação entre esses lugares não é tarefa fácil: "Naturalmente esqueço que vim de lá, que sou um daqueles e posso muito bem, em dado momento, ter sido observado por outrem da mesma forma como faço agora" (Rodrigues, 2004, p. 60).

Olhar a cidade através da janela de um veículo em movimento parece ser uma das imagens representativas de nosso tempo e da própria cidade: o sujeito tende a observar a cidade ao longe, mais do que a se sentir parte dela. Ao definir-se como passageiro em lugar de passante, o narrador de "Translúcida" corrobora essa interpretação. Dessa forma, o narrador, que deixa de "pensar a vida como se fosse um dos passantes" (Rodrigues, 2004, p. 60), atrela sua identidade à do coletivo.

Nas referências feitas pelo narrador à mulher que encontra diariamente no mesmo ônibus, temos a associação entre sujeito e cidade: "Aurora representa para mim o mesmo que o túnel possibilita para a cidade: a 
transição abrupta entre dois mundos diferentes" (Rodrigues, 2004, p. 61). Em seguida, o narrador afirma: "Talvez essa mulher seja a cidade". "Pólis utópica" é outra definição da amada. E ainda: "a minha Aurora, cidade em cujas ruas sinuosas hei de flanar" (Rodrigues, 2004, p. 63).

Com base na leitura de Prosas cariocas, infere-se que, neste século XXI, cidade e sujeito seguem interessando à literatura brasileira, sendo tratados como construções articuladas, em que, por semelhança ou contraste, um pode ser tomado como elemento de representação do outro. As alterações na fisionomia da cidade - por exemplo, o trânsito e o transporte público ou particular - enriquecem as imagens e metáforas que se inscrevem no "livro de registro da cidade", que tem, na literatura brasileira, uma de suas mais preciosas fontes de representação e reflexão sobre a experiência urbana.

\section{Referências}

BATELLA, Juva (2004). A varredura. In: MOUTINHO, Marcelo; IZHAKI, Flávio (Orgs.). Prosas cariocas: uma nova cartografia do Rio de Janeiro. Rio de Janeiro: Casa da Palavra.

BAUMAN, Zygmunt (2001). Modernidade líquida. Rio de Janeiro: Jorge Zahar. GOMES, Renato Cordeiro (1994). Todas as cidades, a cidade. Rio de Janeiro: Rocco. LISPECTOR, Clarice (1980). Onde estivestes de noite. 5. ed. Rio de Janeiro: Nova Fronteira.

(1986). A paixão segundo G.H. 13. ed. Rio de Janeiro: Nova Fronteira.

MOUTINHO, Marcelo; IZHAKI, Flávio (orgs.) (2004). Prosas cariocas. Uma nova cartografia do Rio de Janeiro. Rio de Janeiro: Casa da Palavra.

MOUTINHO, Marcelo (2004). Para ver as meninas. In: MOUTINHO, Marcelo; IZHAKI, Flávio (Orgs.). Prosas cariocas: uma nova cartografia do Rio de Janeiro. Rio de Janeiro: Casa da Palavra.

RAMONEDA, Bianca (2004). Quando se muda. In: MOUTINHO, Marcelo; IZHAKI, Flávio (Orgs.). Prosas cariocas. Uma nova cartografia do Rio de Janeiro. Rio de Janeiro: Casa da Palavra.

RODRIGUES, Henrique (2004). Translúcida. In: MOUTINHO, Marcelo; IZHAKI, Flávio (Orgs.). Prosas cariocas: uma nova cartografia do Rio de Janeiro. Rio de Janeiro: Casa da Palavra.

PESAVENTO, Sandra Jatahy (1999). O imaginário da cidade. Porto Alegre: Editora da UFRGS.

Recebido em dezembro de 2012. Aprovado com alterações em abril de 2013.

Reapresentado em junho de 2013.

Aprovado em junho de 2013. 


\section{resumo/abstract}

\section{Contribuições da literatura brasileira contemporânea ao "livro de registro da cidade"}

\section{Vera Lúcia Cardoso Medeiros}

Este artigo desenvolve análise sobre a representação da cidade em contos e romances da escritora Clarice Lispector de diferentes períodos, buscando identificar quais as principais questões ressaltadas pela autora, bem como as relações que se estabelecem entre o sujeito, a rua e a cidade. Em um segundo momento, será proposta leitura do mesmo tema na obra Prosas cariocas, organizada por Marcelo Moutinho e Flávio Izhaki e publicada em 2004, procurando estabelecer relações com a obra de Lispector e, dessa maneira, perceber se, entre a segunda metade do século $X X$ e o início do século XXI, foram registradas alterações significativas na representação que a literatura brasileira tem feito da cidade.

Palavras- chave: sujeito, cidade, representação, Clarice Lispector, Prosas cariocas.

\section{Contributions of the Brazilian contemporary literature to the "book of the city records"}

\section{Vera Lúcia Cardoso Medeiros}

This article develops an analysis of the representation of the city in stories and novels by writer Clarice Lispector from different periods, trying to identify what the main issues highlighted by the author as well as the relationships established between the subject, the street and the city. In a second step, it is proposed reading of the same theme in the work Prosas cariocas, organized by Marcelo Moutinho and Flavio Izhaki and published in 2004, seeking to establish relationships with Lispector's work and, thus, understand if, between the second half of the century twentieth and early twenty-first century, there were significant changes in representation that literature has made Brazilian city.

Keywords: subject, city, representation, Clarice Lispector, Prosas cariocas. 